Original Article

\title{
The effect of peculiar complex core balance training on isokinetic muscle functions of the knee and lumbus
}

\author{
Myungsun Lee, $\mathrm{PhD}^{1)}$, Gunsoo Han, $\mathrm{PhD}^{2)^{*}}$ \\ 1) Department of Physical Education, Chungnam National University, Republic of Korea \\ 2) Department of Sports and Leisure Studies, College of Humanity, Daegu University: Jillyang, \\ Gyeongsan, Gyeongbuk 38453, Republic of Korea
}

\begin{abstract}
Purpose] This study aimed to investigate the effect of peculiar complex core balance training on the isokinetic muscle function of the knee joint and lumbus to provide fundamental data for establishing a training program that focuses on improving the performance and prevention of injury by developing the core and low extremity muscles. [Subjects and Methods] The participants in this study included a total of ten high school athletes involved in a throwing event for over five years. The subjects were randomly divided into two groups: The experimental group $(\mathrm{N}=5)$ and the control group $(\mathrm{N}=5)$. The experimental group underwent peculiar complex core balance training. [Results] According to the analysis of covariance, there was a significant effect of peculiar complex core balance training. Therefore, the isokinetic muscle function of the knee joint and lumbus in the experimental group participating in peculiar complex core balance training was significantly increased compared to the control group. [Conclusion] It is concluded that peculiar complex core balance training had a positive effect on the isokinetic muscle function of the knee and lumbus in throwing event athletes.

Key words: Isokinetic muscle function, Knee, Lumbus
\end{abstract}

(This article was submitted Dec. 9, 2015, and was accepted Jan. 8, 2016)

\section{INTRODUCTION}

A throwing event is a sports competition that displays a player's ability to throw an object, such as a shot put, discus, javelin, or hammer. To achieve a high level of performance in this sport, total physical fitness, including explosive muscle power, flexibility, agility, and coordination is required ${ }^{1)}$. In particular, core and low extremity muscles are considered to be important muscles for creating a greater rotatory force and maximum speed ${ }^{2,3)}$. The core muscle is found to improve the performance of athletes by increasing balance, as well as trunk and lower extremity strength in various sports, including short-distance running, volleyball, and golf, as core muscle training exercises enhance the stability of the lumbus and spine balance by increasing the musculus transversus abdominis contraction ${ }^{4-9}$ ). Moreover, core stability plays a significant role in injury prevention ${ }^{10)}$. Thus, the core exercise program, which maximizes the mobility and stability of the core muscles, is greatly emphasized for athletes ${ }^{11)}$.

Although previous studies examined the effect of core exercises on isokinetic muscle functions in various sports ${ }^{5-8,12)}$, only limited studies are available to establish an effective and practical muscle training program focusing on throwing events in particular. Therefore, this study aimed to investigate the effect of peculiar complex core balance training on isokinetic muscle function of the knee joint and lumbus to provide fundamental data for establishing a training program that improves the performance and prevention of injury by developing the core and low extremity muscles.

\footnotetext{
*Corresponding author. Gunsoo Han (E-mail: gunsoo@gmail.com)

(C)2016 The Society of Physical Therapy Science. Published by IPEC Inc.

This is an open-access article distributed under the terms of the Creative Commons Attribution Non-Commercial No Derivatives (by-nc-nd) License $<$ http://creativecommons.org/licenses/by-nc-nd/4.0/>.
} 
Table 1. Peculiar complex core balance training program

\begin{tabular}{|c|c|}
\hline \multicolumn{2}{|c|}{ Stage 1 (Week 1-4) Program } \\
\hline Core exercise & Sling exercise \\
\hline $\begin{array}{l}\text { Straight Leg Lifts, Twisted waist oblique Crunches, Butt Raises, } \\
\text { Shoulder-to-Knee Leg overs, Side To Side Planks, Plank With } \\
\text { Hip Drops, Around The World Plank, Bridge Plank, Straight } \\
\text { Plank, Mountain Climbers, Side Plank Hip Abduction With a } \\
\text { Twist, Spiderman Plank, Side Planks With Reach }\end{array}$ & $\begin{array}{l}\text { Suspended Plank, Suspended Single Plank, Suspended Double } \\
\text { Pike, Reverse, Climber, Outsiders, Roll-outs, Bicep Curl, Push } \\
\text { Curl, Single-Leg Lunge, Hamstring Curl, Hip - Raise, Oblique } \\
\text { Twist, Tricep Extension, Rear Deltoid, Captain America Workout }\end{array}$ \\
\hline \multicolumn{2}{|c|}{ Intensity $=\mathrm{RPE} 13-14,10 \mathrm{rep} \times 3 \mathrm{set}$; Duration $=50 \mathrm{~min} ;$ Rest $=1 \mathrm{~min}$ between set } \\
\hline \multicolumn{2}{|c|}{ Stage $2($ Week 5-10) Program } \\
\hline Core exercise & Sling exercise \\
\hline $\begin{array}{l}\text { Sky Reachers, Sit-up, Feet Up Crunch, Bicycle Pausers, Fast Bi- } \\
\text { cycles, Extended Reverse Crunch, Compound Push up, Burpees, } \\
\text { Dynamic Push up, Leaping Lunges, Bring Knee to elbow on the } \\
\text { way down, Ski Abs, Plank Squats }\end{array}$ & $\begin{array}{c}\text { Bicep Curl, Push Curl, Single-Leg Lunge, Hamstring Curl, Hip } \\
\text { - Raise, Oblique Twist, Tricep Extension, Rear Deltoid, Captain } \\
\text { America Workout, Suspended Crunch } 1 \& 2 \text {, Pendulum } 1 \& 2 \text {, } \\
\text { Standing Body Crunch, Standing Oblique Twist, Suspended } \\
\text { Oblique Crunch }\end{array}$ \\
\hline \multicolumn{2}{|c|}{ Intensity $=\mathrm{RPE} 13-14,15 \mathrm{rep} \times 3 \mathrm{set} ;$ Duration $=60 \mathrm{~min} ;$ Rest $=1 \mathrm{~min}$ between set } \\
\hline \multicolumn{2}{|c|}{ Stage $3($ Week 11-16) Program } \\
\hline Core exercise & Sling exercise \\
\hline $\begin{array}{c}\text { Single Rowers, Supermans, Oppo-Raisers, Bird Dogs, Throw } \\
\text { Downs, Hip to Hip, Hand Walk-outs, } \\
\text { Bicycle Pausers, Plank Push Up, Side Plank Rotation, Side } \\
\text { Planks Reach Throughs, Tricep Dip } \\
\text { Oblique Crunches, Hip Thrust, Grass Hoppers, Russian twist, } \\
\text { Bicycle Crunch }\end{array}$ & $\begin{array}{l}\text { Bicep Curl, Push Curl, Single-Leg Lunge, Hamstring Curl, Hip - } \\
\text { Raise, Oblique Twist, Tricep Extension, } \\
\text { Rear Deltoid, Captain America Workout, Suspended Crunch 1, } \\
\text { Suspended Crunch 2, Pendulum 1, Pendulum 2, Standing Body } \\
\text { Crunch, Standing Oblique Twist, Suspended Oblique Crunch }\end{array}$ \\
\hline \multicolumn{2}{|c|}{ Intensity $=\mathrm{RPE} 13-14,20 \mathrm{rep} \times 3 \mathrm{set}$; Duration $=60 \mathrm{~min}$; Rest $=1 \mathrm{~min}$ between set } \\
\hline
\end{tabular}

\section{SUBJECTS AND METHODS}

A total of ten high school athletes, who have been performing in throwing events for over five years, participated in this study. The subjects were randomly divided into two groups: the experimental group $(\mathrm{N}=5)$ and the control group $(\mathrm{N}=5)$. The experimental group underwent peculiar complex core balance training (60 min/three times a week/16 weeks) while the control group did not participate in such training. All subjects were educated about the content and purpose of the experiment and provided written informed consent before beginning the study. A peculiar complex core balance training program was established based on previous studies ${ }^{13}$ with two sports training and conditioning experts, and three current throwing coaches (Table 1).

The training consisted of 16 weeks of mat, medicine ball, and sling training, focusing on the development of core muscles with three stages, including basic balancing and muscle adaptation (4 weeks), kinetic balancing and muscle development (6 weeks), and complex training of kinetic balancing and muscle development (6 weeks). The intensity of training was decided by rating the perceived exertion (RPE $)^{14)}$. In this study, RPE was retained between 13 and 15 . All subjects underwent measurement of the lower extremity; lumbus muscular strength was measured by isokinetic measurement equipment (Cyber-770, Lumax. U.S.A). All experiments were thoroughly reviewed and approved by the Institutional Review Board of Daegu University. The data obtained were processed using SPSS 20.0. The means and standard deviations of the two groups were calculated, and the analysis of covariance (ANCOVA) was conducted to examine the differences between the groups and between measurement time points. Values of $p<0.05$ were considered statistically significant.

\section{RESULTS}

The results of the ANCOVA indicate a significant effect of peculiar complex core balance training and difference between the experimental and control groups. First, in terms of the change of isokinetic strength of the knee joint, ANCOVA [betweensubjects factor: group (experimental, control); covariate: time (pre-post)] revealed the main effects of group and time in all measurements $(\mathrm{p}<0.05)$, excluding extension of muscle power; the interaction between group and time in extension of muscle power was also significant $(\mathrm{p}<0.05)$ (Table 2$)$.

Secondly, regarding the change of isokinetic strength of the lumbus, ANCOVA [between-subjects factor: group (experimental, control); covariate: time] revealed the main effects of group and time in all measurements $(\mathrm{p}<0.05)$; the interaction between groups and time in flexion of strength $(\mathrm{p}<0.05)$ and extension of muscle power $(\mathrm{p}<0.05)$ were also significant $($ Table 3). Therefore, the isokinetic muscle function of the knee joint and the lumbus in the experimental group was significantly increased compared to the control group. 
Table 2. Result of ANCOVA for knee joint strength and muscle power

\begin{tabular}{|c|c|c|c|c|c|}
\hline Type & & & & Experimental group & Control group \\
\hline \multirow{8}{*}{$\begin{array}{l}\text { Strength } \\
(\mathrm{Nm})\end{array}$} & \multirow{4}{*}{$\mathrm{L}$} & \multirow[b]{2}{*}{ Extension } & Pre & $254.6 \pm 14.2$ & $258.1 \pm 21.6$ \\
\hline & & & Post & $268.4 \pm 17.3^{\dagger}$ & $260.2 \pm 19.7 * *$ \\
\hline & & \multirow{2}{*}{ Flexion } & Pre & $207.0 \pm 11.6$ & $198.3 \pm 11.2$ \\
\hline & & & Post & $224.9 \pm 13.6^{\dagger}$ & $201.2 \pm 18.3^{*}$ \\
\hline & \multirow{4}{*}{$\mathrm{R}$} & \multirow{2}{*}{ Extension } & Pre & $268.4 \pm 20.3$ & $257.4 \pm 21.6$ \\
\hline & & & Post & $270.7 \pm 19.1^{\dagger}$ & $256.3 \pm 96.0^{* *}$ \\
\hline & & \multirow{2}{*}{ Flexion } & Pre & $181.6 \pm 18.3$ & $189.6 \pm 14.2$ \\
\hline & & & Post & $210.1 \pm 21.3^{\dagger}$ & $194.4 \pm 15.7^{*}$ \\
\hline \multirow{8}{*}{$\begin{array}{l}\text { Muscle } \\
\text { Power } \\
(\mathrm{Nm})\end{array}$} & \multirow{4}{*}{$\mathrm{L}$} & \multirow{2}{*}{ Extension } & Pre & $57.2 \pm 14.1$ & $54.1 \pm 10.5$ \\
\hline & & & Post & $72.1 \pm 12.1$ & $56.9 \pm 11.2^{* *}$ \\
\hline & & \multirow{2}{*}{ Flexion } & Pre & $145.2 \pm 10.1$ & $143.5 \pm 16.3$ \\
\hline & & & Post & $158.2 \pm 13.8^{\dagger}$ & $143.8 \pm 17.1^{*}$ \\
\hline & \multirow{4}{*}{$\mathrm{R}$} & \multirow{2}{*}{ Extension } & Pre & $68.1 \pm 17.2$ & $69.8 \pm 10.1$ \\
\hline & & & Post & $75.1 \pm 16.3^{\dagger \#}$ & $70.1 \pm 20.7^{* *}$ \\
\hline & & \multirow{2}{*}{ Flexion } & Pre & $156.2 \pm 10.1$ & $158.1 \pm 09.1$ \\
\hline & & & Post & $162.2 \pm 09.3^{\dagger}$ & $158.4 \pm 17.3^{*}$ \\
\hline
\end{tabular}

Values are mean \pm SD. Significantly different $\left({ }^{* *} \mathrm{p}<0.01,{ }^{*} \mathrm{p}<0.05\right)$ from the experimental group. Significantly different $(\dagger \mathrm{p}<0.05)$ between pre and post in the experimental group. Significant interaction $\left({ }^{\#} \mathrm{p}<0.05\right)$ between group and time in the experimental group

Table 3. Results of ANCOVA for lumbus strength and muscle power

\begin{tabular}{lllcl}
\hline Type & & & Experimental group & Control group \\
\hline \multirow{3}{*}{ Strength } & \multirow{2}{*}{ Extension } & Pre & $297.1 \pm 21.8$ & $288.2 \pm 22.3$ \\
(Nm) & & Post & $317.1 \pm 19.3^{\dagger}$ & $291.3 \pm 22.0^{* *}$ \\
& \multirow{2}{*}{ Flexion } & Pre & $334.2 \pm 17.7$ & $335.2 \pm 20.1$ \\
& & Post & $359.2 \pm 19.1^{\dagger \#}$ & $339.2 \pm 19.2^{*}$ \\
Muscle & \multirow{2}{*}{ Extension } & Pre & $354.1 \pm 22.6$ & $361.2 \pm 20.2$ \\
Power & & Post & $369.1 \pm 18.0^{\dagger \#}$ & $368.1 \pm 11.2^{* *}$ \\
$(\mathrm{Nm})$ & \multirow{2}{*}{ Flexion } & Pre & $321.1 \pm 14.2$ & $319.2 \pm 20.2$ \\
& & Post & $342.2 \pm 20.1^{\dagger}$ & $324.1 \pm 16.3^{*}$ \\
\hline
\end{tabular}

Values are mean \pm SD. Significantly different $\left(* * p<0.01,{ }^{*} p<0.05\right)$ from the experimental group. Significantly different $(\dagger \mathrm{p}<0.05)$ between pre and post in the experimental group. Significant interaction $\left({ }^{\#} \mathrm{p}<0.05\right)$ between group and time in the experimental group

\section{DISCUSSION}

Core exercises mostly include the raising of legs and arms in the supine position to create resistance in the abdomen and waist. Core muscle training also helps athletes develop and maintain total body balance. Throwing, in particular, requires the creation of a unified movement by connecting various steps of positions to maximize the performance, and the core muscles are especially important ${ }^{1)}$. Strong core muscle training is especially important to improve the distribution of kinetic efficiency to the whole body ${ }^{15}$. Core muscle training improves the following fitness components: muscle strength, endurance, agility, speed, balance, and the nervous system, including the vestibular system and the proprioceptive system ${ }^{4,16-18)}$. In this study, peculiar complex core balance training significantly increased the isokinetic strength of the knee joint and lumbus. This result is consistent with previous studies, which suggest a positive effect of core muscle training on the lower extremity and lumbus muscle reinforcement ${ }^{5-8,12)}$.

According to Yang's study ${ }^{12)}$, a 12-week core training increased isokinetic muscle power of the knee joint and lumbar in short-distance athletes. Kim and Chung ${ }^{5)}$ conducted a 10-week core exercise program for athletes, and found lumbar strength increased. A study by Shin, Kim, and Park ${ }^{6}$ showed that a 4-week core exercise program had a positive impact on lumbar strength in golfers. Han, Kim, and Hyun ${ }^{7)}$ reported that a 12-week specificity core balance training increased the isokinetic muscular functions of the knee joint and lumbar in high school volleyball players. Moreover, Song and Hong's study ${ }^{8)}$ indicated that an 8-week core strengthening program had a positive impact on knee extensor and flexor muscular strength in 
college baseball players.

In conclusion, this study found a positive effect on peculiar complex core balance training on the isokinetic muscle functions of the knee and lumbus in throwing event athletes. Therefore, core balance training would improve the performance of throwing event athletes by improving balance and distribution of kinetic energy through the arms and legs. Hence, establishing an effective core training program that incorporates a mat, medicine ball, and sling training, as this study has utilized, is required for athletes. It is also worthy to note that this kind of core balance training prevents injury as well. Although the results of this study indicated that peculiar complex core balance training develops the isokinetic muscle function in throwing event athletes, more specific and diverse research is necessary to identify how exercises can be integrated into an ideal physical activity program that caters to each athlete's own characteristics (e.g., age, gender, exercise career, and etc.) and type of sport.

\section{REFERENCES}

1) Locatelli E: New Studies in Athletics. Seoul: Korea Athletics Promotion Association, 2010.

2) Jung JH, Kim JT: Comparative analysis on muscle function and EMG of trunk and lower extremity in short and long distance athlete. Kor Soc Sport Biomech, 2012, 22: 9-16.

3) O'Shea P: Scientific Principles and Methods of Strength Fitness. Addison Wesley Publishing Company, 1976.

4) Yoon SD, Sung DH, Park GD: The effect of active core exercise on fitness and foot pressure in Taekwondo club students. J Phys Ther Sci, 2015, 27: 509-511. [Medline] [CrossRef]

5) Kim KJ, Chung JW: Effect of 10-week core rehabilitation training on flexibility, isokinetic muscle strength, driver shot performance, and pain in elite golfers with low back pain. Exerc Sci, 2009, 18: 115-124. [CrossRef]

6) Shin CH, Kim M, Park GD: Impact of post-manipulation corrective core exercises on the spinal deformation and lumbar strength in golfers: a case study. J Phys Ther Sci, 2015, 27: 3027-3030. [Medline] [CrossRef]

7) Han DY, Kim KC, Hyun KS: Effect of specificity core balance training on isokinetic muscular functions in high school male volleyball players. J Sport Leis Stud, 2011, 46: 1181-1189.

8) Song YK, Hong SM: The effect of core strengthening on the isokinetic muscular strength in university baseball players. J Coach Dev, 2012, 14: 91-105.

9) Beimborn DS, Morrissey MC: A review of the literature related to trunk muscle performance. Spine, 1988, 13: 655660. [Medline] [CrossRef]

10) Leetun DT, Ireland ML, Willson JD, et al.: Core stability measures as risk factors for lower extremity injury in athletes. Med Sci Sports Exerc, 2004, 36: 926-934. [Medline] [CrossRef]

11) Brill PW, Couzen GS: The Core Program, lst ed. New York: New York Books, 2002.

12) Yang SW: The effect of core training on isokinetic muscle power of knee joint and lumbar joint in short-distance athlete. J Coach Dev, 2014, 16: 81-87.

13) Lee MS, Han DY: The effects of core balance band training on isokinetic muscular function of knee and lumbar joints in elite women throwing players. J Sport Leis Stud, 2011, 43: 801-810.

14) American College of Sports Medicine, editor.: ACSM's Health-related Physical Fitness Assessment Manual. Lippincott Williams \& Wilkins, 2013.

15) Sato K, Mokha M: Does core strength training influence running kinetics, lower-extremity stability, and 5000-M performance in runners? J Strength Cond Res, 2009, 23: 133-140. [Medline] [CrossRef]

16) Lee KO: The effect of aerostep and weight training on elderly's balance, physical strength, posturing. Kor J Health Promot Autumn Conference, Seoul, South Korea, 2006.

17) Park EK: The Effects of Core Stability Exercises with Aero-Equipment on Fitness, Gait Development, EMG, fMRI in Stroke Patients. Unpublished Doctoral dissertation, Ewha Womans University, 2008.

18) Kang KY: Effects of core muscle stability training on the weight distribution and stability of the elderly. J Phys Ther Sci, 2015, 27: 3163-3165. [Medline] [CrossRef] 